\title{
Prevalence of Malarial Fever in Local Area of Mansehra
}

\author{
Muhammad Zahid khan ${ }^{*}$, Shahid Iqbal ${ }^{1}$, Mujaddad Ur Rahamnn', Azam Hayat1, Ayub Jadoon ${ }^{1}$, Nusrat \\ Shaheen ${ }^{1}$, Muahmmad Mehran Anjum ${ }^{2}$ and Nawab Ali ${ }^{2}$ \\ ${ }^{1}$ Department of Microbiology, Abbotabad University of Science and Technology, Pakistan \\ ${ }^{2}$ Department of Agronomy, The University of Agriculture Peshwar, Pakistan
}

Submission: March 14, 2017; Published: March 22, 2017

*Corresponding author: Muhammad Zahid khan, Department of Microbiology, Abbotabad University of Science And Technology, Pakistan, Email: Shahidpharma01@gmail.com

\begin{abstract}
Malaria is one of the most severe life threatening disease worldwide. It is a leading cause of death and disease in many developing countries, where young children and pregnant women are the groups most affected. The methods of molecular biology, immunology, and cell biology are now being used to develop an antimalarial vaccine. The Plasmodium parasites that cause malaria have many stages in their life cycle. Each stage is antigenically distinct and potentially could be interrupted by different vaccines. However, achieving complete protection by vaccination may require a better understanding of the complexities of B- and T-cell priming in natural infections and the development of an appropriate adjuvant for use in humans. In fact, new antibiotic and possible vaccine are needed but the importance of effective anephelos mosquitoes control and education of the community is compulsory. Malaria kills 3000 children everyday world wide. In Pakistan, half million malaria cases occur annual are more affected in Khyber pakhtunkhwa province especially in distract Mansehra. Malaria is cause of estimated 50000 deaths each year worldwide mostly in infants, children and pregnant women, he added. In countries where Malaria is common, women are 4 times more likely to suffer malaria attacks during pregnancy resulting in low weight babies and stillbirths. Moreover, nearly $60 \%$ of miscarriages in hyper endemic areas are also due to malaria. Morocco a Muslim country remarkably reduced malaria cases to $00 \%$ Vector control measures; strong political will and Community participation are main way to reduce malaria transmission at the community level. It is the only intervention that can reduce malaria transmission from very high levels to close to zero. Malaria in Mansehra was mainly caused because of a lack of awareness and improper sewerage system and also unhygenic conditions. For this, a proper method of prevention and treatment should be designed which not only provide benefit to the patient and facilitate the physician but also provide an important socioeconomic benefit to everyone.
\end{abstract}

Keywords: Malaria; Anephelos mosquitoes

\section{Introduction}

The word malaria is a combination of two Italian words "Mala" means bad and "Aria" means the air [1]. It was the belief of that time (in 1753) that the bad air transmits the disease, inhalation of poisonous gases emanating from a marshy place was supposed to be the chief factor [2]. About Seven Million years ago, Malaria was identified as one of the most serious and deadliest among blood infections, particularly found in Chimpanzees, but in few hundred thousand years it was observed that malaria not only attacks on chimpanzees but also targets human beings swell [3]. Malaria is documented in a Chinese medical document Nei Ching (Canon of the drugs) about 2700 BC. Nei Chinwags abbreviated by Chinese royal leader "Huang Ti" in which several clinical signs and symptoms were named as Malaria.

In Fourth century BCE Malaria killed a large number of populations in Greece, hence it was hot issue of that time [4]. Ancient Greeks starts studies on Malaria. Empedocles of
Agrigentum in 550 BC, Homer in 850BC while Hippocrates in 400 $\mathrm{BC}$ became conscious of the Malarial Signs and symptoms like Poor Health of the patients living in Marshy places, Enlargement of the Spleen and fevers etc. [5] Malaria was then called "fever and ague" in United States, because that time early American people were unaware about the parasites that transmits malaria [6]. USA has no historical roll in the tragedy of Malaria. It was estimated that in USA Malaria incidence was very high in 1875. But after 1914 more than 600,000 occurs per year. During Vietnam War and the World War II, Malaria was a serious issue in USA military campaigns. US military lost more time due to malaria than to ammunition and bullets [6].

In 1880 a French military doctor Charles Louis Alphonse Laveran examined the blood of a human being infected with Malaria and found Parasites in Red Blood Cells. For his discovery he was rewarded in 1907 with Nobel Prize [4]. An Italian 
neurophysiologist Camillo Golgi (discoverer of the Golgi Bodies in the cell) suggested that the parasites (merozoites) that reside in the RBCs, upon maturity produce a large number of new parasites which are releases in the bloodstream. He also observed that there are about 2 types of the malaria infection, one with the fever of every other day (tertian periodicity) and a new with the fever of every 3rd day (quartan periodicity) In 1890 Raimondo Filetti and Giovanni Batista Grassi introduced the terms Plasmodium malariae and Plasmodium vivax for two of the malarial parasites whichattacks on human [4].

Laveran believed that there was only one specie that infects human being and named it as Oscillariamalariae but later on in 1897 William H. Welch identified malignant tertian malaria parasite and named it as Plasmodium falciparum. In 1922 Plasmodium knowlesi and Plasmodium ovale were identified by Biraj Mohan Das Guptaand Robert Knowles in longtailed macaques (Monkeys). In 1965 the first case of human infection with Plasmodiumknowlesi was reported. Later on in an experiment Giuseppe Bastianelli and Amico Bignami collected mosquitos of the specie Anopheles claviger and they were fed by Plasmodium. As a result, an absolute sporogonic round of Plasmodium malariae, P. vivax and P. falciparum was observed. In 1899 ,infected mosquitoes that were fed by a patient in Rome, they were sent to London where they fed on 2 volunteers, as a result of which both of them were infected by malaria [4].

\section{Malaria Parasite}

A Single cell protozoon parasite which belongs to genus Plasmodium is the main cause of malarial infection. More than one hundred species of Plasmodium exists which cause malaria in humans, birds, reptiles and in chimpanzees' as well. There are about four species of plasmodium that infects human beings i.e. Plasmodium vivax, Plasmodiumfalciparum, Plasmodium malariae and Plasmodium ovale [7]. Moleculer studies revealed that Plasmodium vivax is derived from an antientparqaa site of macaque from Africa [8]. All the Malarial parasites have different morphologies and appearances, and can be differentiated from one another. They also cause different clinical symptoms [9] .

In high endemic areas there are many chances of multiple infections. At the same time two or more than two species of a parasite may attack a single host [9]. Among all plasmodium species, Infection with the Plasmodium falciparum is deadliest because of its severity of infection and serious complications $[10,11]$. It causes life threatening fever that leads to high level mortality in a population [9]. Any stage of the Red Blood Cells can be easily invaded by Plasmodium Falciparum which results in high parasitemia that makes it a virulent Parasite. Cerebral malaria, black water fever, non-cardiopulmonary edema, lower Glucose level, Anemia and acute renal failure are the most serious clinical manifestations that are linked with the infection of P. Falciparum $[10,11]$.
The multiplication of the parasite is so high that they become twenty fold just in two days [12]. Plasmodium vivax is the $2^{\text {nd }}$ most common parasite that is distributed worldwide and comparatively less severe than P. Falciparum P. vivax is mostly found in tropical areas especially in entire Asia [13]. P vivax affects about 75 million people worldwide. Most of the cases are in S. America and Asia [9]. Relapse cases of the Plasmodium vivaxcan occur up to 3 years [13]. Infection of the Plasmodium ovale is very rare, but sometimes found in W. Africa. Plasmodium malariae is eliminated from temprate regions, aperson who is infected with the Plasmodium malariae may be asymptomatic (show no symptoms), and the Plasmodiummalariae can stay in the blood for decades without anymalarial signs and symptoms [13]. In Pakistan only two species of Plasmodium are dominant i.e. Plasmodium falciparum and Plasmodium vivax [14].

\section{Vector of the Malaria Parasite}

In 1897 a British officer Ronald Ross studied on birds and mosquitoes, and suggested that malaria can be transferred from infected bird to healthy bird through Anopheles mosquito. This study revealed the secrets of the life cycle of the parasite that a part of the life of Plasmodium is spent in mosquitoes, later on it was termed as Sporogonic Cycle. Ronald Ross was then rewarded by Nobel Prize in 1902for his discovery [4].

Major vectors for the transmission of Plasmodium are Anopheles funestus, A. bwambae, A. nili, A.merus, A. arabiensis and A. gambiae. About six other speciesin A. gambiae also act as vectors of malarial infection in South and Eastern Africa [1517]. Genus Anopheles of mosquitoes is an important vector of plasmodium transmission on islands and coastal areas of Southeast Asia. Molecular studies showed a large number of polymorphism in A. funestus, An. Gambiae and A. arabiensis [18].

\section{Vectors of Malarial parasites in Pakistan}

Studies were conducted on the Plasmodium vectors of Pakistan which resulted that there are about 24 species of anopheles mosquitoes including A. sergenti, A. pulcherrimus,

A. subpictus, A. dthali, A. culicifacies, An. pallidus, A. turkhudi, A. annularis, A. fluviatilis, A. stephensi, A. superpictus, A. multicolor, A. willmori, A. lindesayi, A. moghulensis, A. theobald, A. maculates, A. claviger, A. gigas, A.barianensis, A. splendidus, A. barbirostris, A. nigerrimus.

B. peditaeniatus, A. culicifacies and A. stephensi are the species that gain resistance to many of the insecticides including Dieldrin, DDT, carbamates and organophosphates(malathion, fenitrothion) [19]. Primary vector species in Pakistan are A. culicifacies and A. Stephensi [20-23]. In Khyber Pakhtunkhwa province of Pakistan, a large number of $A$. stephensi and $A$. culicifacies were reported as vectors of plasmodium [24]. But the number of A. stephensi is much more then Anopheles culicifacies. 
Anopheles culicifacies is dominant in Punjab province of Pakistan. It is more active before September while it disappears after the month of September [20-24]. An. stephensi is a subtropical species which is distributed in the entire the middle east and South Asia. In Arid and Semi -arid zone of Rajasthan and Gujarat A. subpictus Grassi were found to be more common species [25]. An. stephensi is an exclusive vector of malaria in Pakistan, India and in Afghanistan. It has an amazing characteristic of proficient breeding in underground water reservoirs mostly in urban areas [26].

\section{Epidemiology}

Malaria is a tropical disease which worldwide distributed mostly in tropical areas, in entire Sub-Saharan Africa and in South Africa, South America Southeast Asia, India, Central America and Pacific Islands. Pakistan is located in the middle of the malaria belt around the globe encompassing tropical and subtropical areas [27]. Malaria cause approximately 8,63,000 deaths in 2008 and About 243 million malaria cases are reported every year [28]. About 1.2 billion populations ofthe Pacific countries and South East Asia are at higher risk of malarial transmission, representing about one third of total world population [29,14].

There are about 109 of malaria-endemic countries, where about 3.3 billion people are at risk for malaria. 50\% of global population at risk for malaria, whereas $90 \%$ deaths in Africa are caused by Malaria in which 5.85\% are children [30]. Plasmodium vivax is chiefly a widespread cause of malaria in Asia and Central and South America [31]. Probable figure of yearly malaria episodes in Pakistan is 1.5 million [28]. Plasmodiumvivax is internationally distributed and is the chief species in many countries $[29,14] 2.6$ billion Population is at risk of vivax infection throughout the world [31]. Infection by Plasmodium vivax is generally regarded as benign malarias with low mortality level $[29,14]$. On the other hand, the rate of infection of the P. falciparum is comparatively narrower than that of Plasmodium vivax but it is the serious cause of mortalities in Pakistan. In 2005 , falciparum malaria was one of the 33percent of reported definite malaria cases, this rate reduced to 24 percent in 2008 [28].

In 2004 the number of malaria cases were 103,416, in 2006 they were 124910 , in 2007 they were 128570 while in 2008 the number of malaria cases were 104454 (WHO, 2005). Pakistan is a tropical country with the improper irrigation and dumping of garbage system and other wastes. Majority of the population of Pakistan live in rural areas where there is unhygienic environment, all these factors leads to malariogenic potential [29]. Because of a countrywide malaria eradication fight in 1961, malaria was almost eradicated in Pakistan for the period of 1960s with 9500 positive cases in 1967 but due to Financial and administrative crises and political disturbances Malaria again arouse in 1970s reaching epidemic level in 1972-73 [30].
It is estimates that the rate of malarial infections is enlarged by 40 percent in the middle of 1970 and 1997 in sub-Saharan Africa [31]. While the number of deaths due to malaria worldwide has decreased from 985,000 in 2000 to 781,000 in [32]. To deal with this infection, public health personnel selected cautiously many avoidance methods appropriate to a exacting area or environment [6] Latest studies reveled that there were 225 million cases of malarial infection and an estimated 781,000 deaths reported in 2009 [33].

About 300-500 million people infected with the malaria infection while 1.1 - 2.7 million deaths occur worldwide annually. Children under age group $<5$ years are more susceptible for the mortality rate caused by malarial infection. In 2004, 20 percent deaths of the children were reported [33]. In Eastern Mediterranean Region (EMR), there were 5.7 million confirmed malaria cases, of which $17 \%$ cases were registered in Pakistan [34]. In 2010, Due to flood estimated cases reported from Pakistan [35]. In 2003 Malaria control program stated serious outbreaks in many districts. This may clarify the elevated rates of authenticated cases in 2002 and 2003 in KP. By 2005 guidance had been imparted in 16 districts of KP. Improved investigative techniques (diagnostic tools) could have condensed false identification, and afterward report for the decrease in figure of confirmed malaria cases after 2003, and the outbreaks could have been controlled [36-41].

\section{Transmission of the Parasite}

Ronald Ross discovered in 1897 that the avian malaria parasite Plasmodium relictum transmitted by culicinemosquitoes. He suggested that human malaria may also be transmitted by mosquitoes. After his study and research then he proved that human malaria is indeed transmitted by anopheline mosquitoes. It was proved by many of the Italian scientist. Ross was a wellknown military medical doctor he was operational in India till 1894 he didn't believed that a parasite is the cause of malarial infection that resides in blood, but Manson proved him with the malarial positive slides that this infection is actually a blood infection that is transmitted by blood meal of female Anopheles mosquito [5].

\section{Life Cycle}

\section{Asexual Stage}

Asexual stage begins when a female Anopheles mosquito (infected with malaria) bites a healthy human being and infuses the sporozoites in the bloodstream of that healthy person. These sporozoites move in the hepatic circulation and attack the liver cells [5].

\section{Incubation Period}

Incubation Period of the Plasmodium vivax \& P. ovale is 14 days, P. falciparum 12 days while P. malariae has 30 days [4]. 


\section{Orthopedics and Rheumatology Open Access Journal}

\section{Exoerythrocytic Schizogony}

In liver cells sporozoites undergoes multiple rounds of asexual division as a result of which many uninucleated merozoites are produced. These merozoites released in the general circulation and attack on Red Blood Cells [5].

\section{Erythrocytic Schizogony}

Merozoites invade $\mathrm{RBCs}$ and each merozoite undergoes second phase of asexual multiplication as a result of which 8-16 new merozoites are produced in each RBC. Each new merozoite again invades a new RBC, this cycle continues and clinical manifestations (fever, Headache, Anemia) are appeared [5].

\section{Gametogony}

Some of the young merozoites are transformed into gametocytes (male and female) that flow in the peripheral bloodstream until they are gulp by a female anopheles' mosquito during blood meal [5].

\section{Sexual Stage}

In the gut of the mosquito ex-flagellation of the male gametocytes takes Place. Then both the male and female gametocytes become fuse together and converted in to a motile zygote. Zygote is then transformed into ookinete [5]. The ookinete then penetrate the wall of the gut and converted in to a conspicuous oocyst, which is then converted in to spookiest. Spookiest results in the development of sporozoites which migrate towards the salivary glands of female anopheles mosquito and are ready to be infuse in to the new host during blood meal of the mosquito [5] The life cycle of the plasmodium within the mosquito is about 8-35 days, after [4] Sometime the malarial parasites become dormant in the host body, show no signs and symptoms (Hypnozoite stage) parasite wakes up suddenly and cause attacks of malarial fever [42]. Human malaria is caused by any species of the plasmodium [43]. But In spite of human the parasitic Plasmodium species also infect rodents, birds, monkeys, chimpanzees and reptiles [44]. Number of White Blood Cells becomes low in the malaria infection [45].

\section{Symptoms}

Clinical symptoms and manifestations appear in the asexual stage of the parasite, mostly in Erythrocytic cycle when the parasite reproduces in Red Blood Cells. Parasite count in the blood is directly proportional to the clinical presentations [46]. Sometime the parasite remains inactive in the human body, intemperate areas one out of five cases of Plasmodium vivax began relapse in a year after mosquito bite, which is called thehypnozoite stage of the parasite [47]. Neutrophils are activated in the infection of Plasmodium falciparum which results in endothelial damage and organ failure [48]. Other clinical presentations in the Malaria infection includes Temperature, Headache, juindus, enlargement of spleen and liver, thrombocytopenia (platelets deficiency), diarrhea, apnea, respiratory distress [49].
Hemolysis cytokine disturbances and decreased rate of RBC production and maturation which leads to anemic condition or dyserythropoiesis (defective development of erythrocytes) [50]. Enlargement of spleen may lead to death of an individual [51]. Plasmodium infection is a major cause of paediatric anaemia in malaria patients. During Erythrocytic cycle when RBCs are under attack, Haemoglobin concentration becomes lower due to RBC destruction and also due to the removal of parasitized and nonparasitized RBCs [52]. When the Haemoglobin level become less or equal then $11.0 \mathrm{gm} / \mathrm{dl}$ then this condition may be termed as mild anaemia [52]. This criterion was used 1995 to investigate the anaemia burden [53]. When the Hb level becomes 7- $8 \mathrm{gm} /$ $\mathrm{dl}$, that condition is called moderate anaemia while if it is less than $5 \mathrm{gm} / \mathrm{dl}$ then the anaemia is called severe anaemia [52].

\section{Methodology}

\section{Malaria Parasite Diagnosis}

Diagnosis of malaria includes identification of Plasmodium or its antigens within the blood of the infected person. Malaria may be diagnosed by various techniques available commercially [54].

\section{Microscopy}

A gold standard technique and established method for the diagnosis of malarias is the Microscopy. But without technical expertise it may not produce a good result [55]. It is based on finger pricked blood which is poured on a slide, thin and thick blood films are prepared. Giemsa stain is used for staining then with the help of immersion oil slides are examined under x100 lens of the compound microscope [56,57]. But here me used only strip method for both Plasmodium vivax and Plasmodium falciparum against malarial patients in Mansehra during my four months of work.

\section{Rapid Diagnostic Test}

RDT tests are based on the finding of antigens of the malarial parasites in RBCsby using animmunochromatographic technique. RDT also called Immunochromatographic Technique (ICT). It is based on antigen-antibody interaction. For the field diagnosis it is very good and sensitive diagnostic technique. Malaria diagnosis is improved with the help of worldwide implementation of RDTs $[28,58]$. ICT tests that detect P. falciparum are based on histidine rich protein 2 (HRP-2), that is specific to P. falciparum While those that detect P. vivax are based on Plasmodium aldolase and Plasmodium lactate dehydrogenase (LDH) detection using monoclonal antibodies which start reaction with LDH of all species including P. falciparum. Trophozoites and gametocytes of the P. falciparum produced Histidine-richprotein II (HRP-II) which is a water- soluble protein. HRP-2 may persist in the blood for days or weeks after treatment, whereas LDH is only detected if live parasites are present. Parasite lactate dehydrogenase (pLDH) is an enzyme which is produced by gametocytes of plasmodium. 
Currently Test kits are available to detect pLDH from all four Plasmodium species. They can distinguish P. falciparum from the non-falciparum species, but cannot differentiate between $P$. vivax, P. ovale and P. malariae. Some of the RDT kits detect all four malarial parasites mention in their brand name or their marketing material only two species i.e. "PF/PV". This lead to confusion about their diagnostic capabilities [59]. ICT tests are obtainable in many designs like plastic cards, cassettes or dipsticks. The quality of the ICT format depends upon producer as well as on conditions in which it is being stored. This test is 90 percent more sensitive than microscopy. For the field diagnosis RDT/ ICT can tolerate temperature and humidity depending upon the manufacturer [58].

\section{Mode of action}

RDT format consists of a nitrocellulose strip, on which dye labeled specific antibodies are coated on a thin line for malarial antigen. And either antibody specific for the labeled antibody, or antigen, is bound at the control line. A drop of blood is poured on the nitrocellulose strip then a buffer is also added which flush the blood towards the antibodies. RBCs are lysed and the parasite antigen becomes naked and mixed with the labeled antibody. If there is specific antigen, that will react with the antibody on the strip and become visible in the test line. While other labeled antibodies will be tapped on the control line [32].

Results

\section{A list of positive malarial fever patients of local area of Mansehra}

During four months of work, 100 fever suffering patients were handled, there were only some patient that suffer from malarial fever. There are total 29 patients of malarial fever out of 100. In 29 malaria patients only 5 patient were suffering from $P$. Falciparum which is most severe and life threatening condition of malaria (Table 1).

Table 1: A list of positive malarial fever patients of local area of Mansehra

\begin{tabular}{|c|c|c|c|c|}
\hline S.No & Patient I.D & $\begin{array}{c}\text { P. } \\
\text { falciparum }\end{array}$ & P. vivax & \\
\hline 1. & & 103 & & + \\
\hline 2. & & 108 & & + \\
\hline 3. & & 148 & & + \\
\hline 4. & & 149 & & + \\
\hline 5. & & 160 & & + \\
\hline 6. & & 209 & & + \\
\hline 7. & & 212 & + & - \\
\hline 8. & & 232 & & + \\
\hline 9. & & 290 & & + \\
\hline 10. & & 300 & & + \\
\hline 11. & & 309 & & + \\
\hline 12. & & 323 & + & - \\
\hline 13. & & 325 & & + \\
\hline
\end{tabular}

\begin{tabular}{|c|c|c|c|c|}
\hline 14. & & 380 & & + \\
\hline 15. & & 417 & & + \\
\hline 16. & & 470 & & + \\
\hline 17. & & 476 & & + \\
\hline 18. & & 480 & & + \\
\hline 19. & & 497 & & + \\
\hline 20. & & 498 & + & - \\
\hline 21. & & 510 & & + \\
\hline 22. & & 512 & & + \\
\hline 23. & & 518 & & + \\
\hline 24. & & 532 & + & - \\
\hline 25. & & 543 & & + \\
\hline 26. & & 555 & & + \\
\hline 27. & & 566 & + & - \\
\hline 28. & & 578 & & + \\
\hline 29. & & 589 & & + \\
\hline
\end{tabular}

\section{Treatment}

For the development of malarial drugs sexual stages malarial parasites were cultured but they gain resistance to drug, as culturing of liver stages, were extra hard to accomplish, made it probable to build up and experimentally test the drugs in opposition to this stage, this provided significant information about the immune reaction in the liver. Finally, the culture of sporogonic stages has enabled researchers to discover that in the mosquito vector what happens to the parasite [5].

\section{Two types of Treatment}

i. Allopathic: Drugs that is required for malarial treatment includes sulfadoxine/pyrimethamine, mefloquine, atovaquoneproguanil, quinine or quinidine, clindamycin, doxycycline, chloroquine, and primaquine [60]. The artemisinin are the most effective medicines that have ever been invented for [32]. A lot of work has been done on malarial vaccines with limited success [61]. The circum sporozoite protein (CSP) is an antigen that is present on the outside of sporozoites, has been used broadly as an objective for the development of vaccines [62].

Intermittent preventive treatment (IPT) that is taken time to time regardless of malarial infection is recommended by the World Health Organization especially for pregnant women. IPT immune the body for the specific parasite encounters [43]. Malaria, especially Falciparum malaria, is a medical emergency that requires a hospital stay. Chloroquine is often used as an antimalarial medication. However, chloroquine-resistant infections are common in some parts of the world. Possible treatments for chloroquine-resistant infections include:

I. The combination of quinidine or quinine plus doxycycline, tetracycline, or clindamycin

II. Atovaquone plus proguanil (Malarone)

III. Mefloquine or artesunate 
IV. The combination of pyrimethamine and sulfadoxine (Fansidar)

The choice of medication depends in part on where you were when you were infected.

Medical care, including fluids through a vein (IV) and other medications and breathing (respiratory) support may be needed.

\section{ii. Homeopathic}

a. Advantage of Homeopathic Treatment: Homeopathy is the science that takes a holistic approach to healing. Natural and safe, Homeopathic medicines are deep acting and have no side effects on the body. Unlike the conventional mode of medicine, Homeopathic medicines do not suppress the disease and its symptoms. In fact, they attack the disorder at the root and set off the body's own restorative processes, making it strong enough to completely eradicate the disease. Supressing the disease process makes it stubborn. Homeopathic medicines are a natural, healing alternative [62].

b. Homeopathic Medicines for Malaria: Top rated Homeopathic medicines for malaria are China, Arsenic Album and Chininum Sulphuricum. China is one of the most prescribed Homeopathic medicines for malaria at any stage of progression. The symptoms to look out for include chill in the mornings with debilitating night sweats. In malaria cases with high temperature with marked periodicity and great restlessness Arsenic Album shows the best results. Chininum Sulphuricum is most effective in malaria cases with great chill and shivering in the body $[61,62]$.

a) Chininum Sulphuricum and Nux Vomica Homeopathic medicines for malaria with marked chill and shivering (cold stage): Chininum Sulphuricum and Nux Vomica are two well indicated Homeopathic medicines for malaria with marked chilliness and shivering (cold stage). Chininum Sulphuricum is very effective where the chill occurs at $3 \mathrm{pm}$ every day. The person experiences great shivering even in a warm room. For malaria in the cold stage, with blueness of fingernails, Nux Vomica is recommended as one of the most effective Homeopathic medicines. Also, in cases where the person feels chilliness on being uncovered, yet will not want to be covered, Nux Vomica is prescribed as one of the most effective Homeopathic medicines for malaria [62].

b) Boletus and Eupatorium Perfoliatum - Top Homeopathic medicines for malaria with profuse sweating (sweat stage): The most useful Homeopathic medicines for malaria with profuse sweating (sweat stage) are Boletus and Eupatorium Perfoliatum. Homeopathic medicine Boletus is prescribed in malaria cases with profuse perspiration, especially at night, along with severe chills and fever. Eupatorium Perfoliatum works as one of the best Homeopathic medicines for malaria cases where all complaints, except headache, are relieved by perspiration. The person experiences chills, mostly between 7 am and 9 am, preceded by strong thirst and aching bones [62].

c) Arsenic Album and China - Best Homeopathic medicines for malaria with high fever (heat stage): Malaria with high fever (heat stage) is attended well with Homeopathic medicines Arsenic Album and China. Arsenic Album is one of the most excellent Homeopathic medicines for malaria with high grade fever with marked periodicity. Great restlessness accompanying high fever that gets worse after midnight is also treated well with Arsenic Album. China is one of the most effective Homeopathic medicines for malaria with high temperature that returns every week. The person complains of chill in the morning with debilitating night sweats [62].

d) Natrum Muriaticum and Pulsatilla - Effective Homeopathic medicines for malaria with headache: Natrum Muriaticum and Pulsatilla are rated among the most effective Homeopathic medicines for malaria with headache. Natrum Muriaticum is prescribed in case of continued chilliness along with the headache, especially on waking in the morning. Malaria cases with headache that persists from sunrise to sunset are also best treated with Homeopathic medicine Natrum Muriaticum. In case of chill with pains in certain spots, especially in the evening, Pulsatilla is one of the best Homeopathic medicines for malaria. Complaints of wandering stitches in the head during sweat are also treated well with Homeopathic medicine Pulsatilla [62].

e) China, Alstonia and Ferrum Phosphoricum - Top grade Homeopathic medicines for malaria with notable weakness: The most prescribed Homeopathic medicines for malaria with notable weakness are China, Alstonia and Ferrum Phosphoricum. China acts well in all stages of malarial fever with great exhaustion. Debilitating night sweats with fever that returns every week are also treated well with China, making it one of the sought after Homeopathic medicines for malaria. Alstonia is a great Homeopathic tonic for debilitating and exhausting malarial fever. On the other hand, cases of chill occurring daily at $1 \mathrm{pm}$, with marked prostration, are attended well with Ferrum Phosphoricum, making it one of the most remarkable Homeopathic medicines for malaria.

iii. Prevention: With the discovery mosquitoes in the malaria transmission, provided researches with a new weapon against malaria. It is experimentally proved that by the reducing the contact of the healthy person with the infected persons declines the risk of malarial infection. Other methods to prevent the malarial infection include the distraction of mosquito breeding places, use of anti-mosquitoes oils and use of mosquito nets, appropriate clothing, mosquito repellents, particularly in the evening and after dark (long-sleeved shirts, trousers, socks, etc.) [32].

Biological control includes larvivorous fish that eatupon the lavas of the mosquitoes. Some entomopathogenic bacteria, such as Bacillus thuringiensis serovar. Israelensis (Bti) and 
Bacillus sphaericus (Bsph) are used to control the vectors. Chemoprophylaxis of Malaria is recommended for those people who travel to malaria-endemic areas and travel medical specialists must be contacted before travel. As malaria is a blood infection, blood donors must be properly examined for the history of malarial parasites [4]. People who are taking antimalarial medications may still become infected. Avoid mosquito bites by wearing protective clothing over the arms and legs, using screens on windows, and using insect repellent.

Chloroquine has been the drug of choice for protecting against malaria. But because of resistance, it is now only suggested for use in areas where Plasmodium vivax, P. oval, and P. malariae are present. Falciparum malaria is becoming increasingly resistant to anti-malarial medications. For travelers going to areas where Falciparum malaria is known to occur, there are several options for malaria prevention, including mefloquine, atovaquone/ proguanil (Malarone), and doxycycline.

\section{Conclusion}

From the obtained related study it may be concluded that malaria is a life threatening disease. Prevention and treatment should be designed which not only provide benefit to the patient and facilitate the physician but also provide an important socioeconomic benefit to everyone.

\section{References}

1. Khan MA, Smego RA, Rizvi S, Beg MA (2004) Emerging drug-resistance and guidelines for treatment of malaria. Journal of College of Physicians and Surgeons Pakistan 14(5): 319-324.

2. Pakistan times (2005) Malaria A Serious Threat in Pakistan.

3. Centers for Disease Control and Prevention (2010) Division of Parasitic Diseases. Chiodini, P.L. (1998). Non-microscopic methods for diagnonsis of malaria. Lancet 351: 80-81.

4. Francis EG (2010) History of the discovery of the malaria parasites and their vectors. Parasit Vectors 3(1): 5.

5. Manuel W Hetzel, Nelly Iteba, Ahmed Makemba, Christopher Mshana, Christian Lengeler, et al. (2007) Understanding and improving access to prompt and effective malaria treatment and care in rural Tanzania: the ACCESS Programme. Malar J 6: 83.

6. White NJ (1996) The treatment of malaria. New England Journal of Medicine 335: 800-806.

7. Escalante AA, Cornejo OE, Freeland DE (2005) A monkey's tale: the origin of Plasmodium vivax as a human malaria parasite. National Academy of Science USA 102(6): 1980-1985.

8. Mallika I, Pukrittayakamee S, Grüner AC, Rénia L, Letourneur F, et al. (2005) Practical PCR genotyping protocols for Plasmodium vivax using Pvcs and Pvmsp1. Malaria Journal 4: 20.

9. Mohapatra MK (2006) The natural history of complicated P. falciparum Malaria: a prospective study. Journal of the Associations of Physicians India 54: 848-853.

10. Bhalli MA, Samiullah (2001) Plasmodium falciparum malaria - a review of 120 cases. Journal of College of Physicians and Surgeons Pakistan (1): 300-303.
11. Rowe JA, Obiero J, Marsh K, Raza A (2002) Short report: positive correlation between resetting and parasitemia in Plasmodium falciparum Clinical isolates. American Journal of Tropical Medicine and Hygiene 66(5): 458-460.

12. National Institute of Health (2011) Cause of Malaria.

13. Hay SI, Guerra CA, Tatem AJ, Noor AM, Snow RW (2004) The global distribution and population at risk of malaria: past, present, and future. Lancet 4(6): 327-336.

14. Gillies MT, Coetzee M (1987) A supplement to the Anophelinae of Africa south of the Sahara (Afro tropical Region). South African Institute for Medical Research, Johannesburg. South African Institute for Medical Research 55: 1-143.

15. Coetzee M, Craig M, Le-Sueur D (2000) Distribution of African malaria mosquitoes belonging to the Anopheles gambiae complex. Parasitology Today 16(2): 74-77.

16. Reid JA (1968) Anopheline mosquitoes of Malaya and Borneo. Studies from the Institute of Medical Research Malaya 31:1-520.

17. Kakar MA, Khan MK, Bile (2001) Malaria and its control in Pakistan. WHO.

18. Malaria Control Program (1999) District-wise Epidemiological Data of Malaria Control Program, Balochistan. MCP Balochistan, Pakistan.

19. Yasinzai MI, Kakarsulemankhel JK (2004) A study of prevalence of malaria infection in urban areas of district Quetta Pakistan. Pakistan Journal of Zoology 36(1): 75-79.

20. Yasinzai MI, Kakarsulemankhel JK (2003) Incidence of malaria infection in rural areas of District Quetta, Pakistan. Online Journal of Medical Sciences 9(3): 766-772.

21. Yasinzai MI, Kakarsulemankhel JK (2004) A study of prevalence of malaria infection in urban areas of district Quetta, Pakistan. Zoology 36(1):75-79.

22. Reisen WK, Boreham PFL (1982) Estimates of malaria vectorial capacity for Anopheles culicifacies and An. stephensi in rural Punjab province, Pakistan. Journal of Medical Entomology 19: 98-101.

23. Dash AP, Adak T, Raghavendra K, Singh OP (2007) The biology and control of malaria vectors in India. Current Science 92: 1571-1578.

24. Dash AP, Raghavendra K, Pillai MKK (2006) Combating Resistance to Insecticides in Malaria Control- Gains Made in India. Bayer Environmental Science Journal18: 30-37.

25. Anwar M Saleem, Zaheeruddin (1994) Malaria a challenge to meet pak armed forces. Pakistan Medical Journal 44:1-3.

26. World Health Organization (2009) World Malaria Report.

27. Mendis K, Sina BJ, Marchesini P, Carter R (2001) The neglected burden of Plasmodium vivax malaria. American Journal of Tropical Medicine and Hygiene 64: 97-106.

28. World Health Organization (2008) World malaria report. 1-190.

29. Guerra CA, Snow RW, Hay SI (2006) Mapping the global extent of malaria in 2005. Trends in Parasitology 22(8): 353-358.

30. Pukrittayakamee S, Imwing M, Looareesuwan S, White NJ (2004) Therapeutic responses to antimalarial and antibacterial drugs in P. vivax malaria. Acta Trop 89(3): 351-356.

31. World Health Organization (2008) Malaria rapid diagnostic test performance: results of WHO product testing of malaria RDTs: round 1.

32. World Malaria Report (2005) Malaria Pp: 294.

33. World Health Organization (2011) World Malaria Report. Malaria. 
34. Nishtar S (2006) The Gateway Paper: Health Systems in Pakistan-away forward. Pakistan's Health Policy Forum and Heart File.

35. Sabina AA (2008) Departmental Audit of Malaria Control Programme 2001-2005 North West Frontier Province (NWFP). Journal of Ayub Medical College Abbottabad 20(1): 98-102.

36. Rowland M (2001) Malaria epidemiology and control in refugee camps and complex emergencies. Annals of Tropical Medicine \& Parasitology 95(8): 741-754.

37. Meara WP, Breman JG, McKenzie FE (2005) The promise and potential challenges of intermittent preventive treatment for malaria in infants. Malaria Journal 4: 33 .

38. Escalante A, Ayala F (1994) Phylogeny of the malarial genus Plasmodium derived from rRNA gene sequences. National Academy of Science USA 91(24): 11373-11377.

39. Tangpukdee N, Yew HS, Krudsood S, Punyapradit N, Somwong W Looareesuwa S et al. (2008) Dynamic changes in white blood cell counts in uncomplicated Plasmodiumfalciparum and P. vivax malaria. Parsatolgy International 57(4): 490-494.

40. Murthy GL, Sahay RK, Srinivasan VR, Upadhaya AC, Shantaram V, Gayatri K (2000) Clinical profile of P. falciparum malaria in tertiary care hospital. Journal of Indian Medical Association 98(4):160-162.

41. Adak T, Sharma V, Orlov V (1998) Studies on the Plasmodiumvivax relapse pattern in Delhi India. American Journal of Tropical Medicine and Hygiene 59(1):175-179.

42. Hemmer JC, Lehr HA, Westphal K, Unverricht M, Kratzius M,et al (2005) Plasmodium falciparum Malaria \& Reduction of Endothelial Cell Apoptosis InVitro. American Society for Microbiology 73(3):17641770.

43. Fischer PR (1997) Congenital Malaria: an African survey. Clinical Pediatrics 36(7): 411-413.

44. Menendez C, Fleming AF, Alonso PL (2000) Malaria-related anaemia. Parasitology Today16(11): 469-476.

45. Snow RW, Guerra CA, Noor AM, Myint HY, Hay SI (2005) The global distribution of clinical episodes of Plasmodium falciparum malaria. The Nature 434(7030): 214-217.

46. De-Maeyer E, Adiels-Tegman M (1985) The prevalence of anemia in the world. World Health Statistics Quarterly 38: 302-316.

47. Park JE (2002) Parks textbook of preventative and social medicine. Prem Nagar, Jabalpur 482001 India 22:186-201.

This work is licensed under Creative Commons Attribution 4.0 License

DOI: $10.19080 /$ OROAJ.2017.05.555662
48. Murray CJ, Lopez AD (1996) Global burden of disease and injury series.

49. World Health Organization (2005) List of known commerciallyavailable antigen-detecting malaria RDTs.

50. Mwanziva C, Shekalaghe S, Ndaro A, Mengerink B, Megiroo S, et al. (2008) Overuse of artemisinin-combination therapy in Mtowa Mbu (river of mosquitoes), an area misinterpreted as high endemic for malaria. Malaria Journal 7: 232.

51. Payne D (1988) Use and limitations of light microscopy for diagnosing malaria at the primary health care level. Bulletin of the World Health Organization 66(5): 621-626.

52. World Health Organization (1990) Severe and complicated malaria. Trans R Soc Trop Med Hyg 84(2): 1-65.

53. Wongsrichanalai C, Barcus MJ, Muth S, Sutamihardja A, Wernsdorfer WH (2007) A review of malaria diagnostic tools: microscopy and rapid diagnostic test (RDT). American Journal of Tropical Medicine and Hygiene 77:119-127.

54. Quintana M (1998) Malaria diagnosis by dipstick assay in a Honduran population with coendemic Plasmodium falciparum and Plasmodium vivax. American Journal of Tropical Medicine and Hygiene 59(6): 868871.

55. Okafor HU, Nwaiwu O (2001) Anemia of Persistent Malarial Parasitemia in Nigerian Children. Journal of Tropical Pediatrics 47(5): 271-275.

56. Grassi B (1900) Studi di uno Zoologo Sulla Malaria. Rome.

57. Bruce-Chwatt LJ (1988) History of malaria from prehistory to eradication. Malaria: Principles and Practice of Malariology Edinburgh. Churchill Livingstone Windsurfer McGregor 1:1-59.

58. Becker N (1998) The use of Bacillus thuringiensis subsp. israelensis (Bti) against mosquitoes, with special emphasis on the ecological impact. Israel Journal of Entomology (32): 63.

59. Fillinger U, Knols BGJ, Becker N (2003) Efficacy and efficiency of new Bacillus thuringiensis var, israelensis and Bacillus sphaericus formulations against Afrotropical anophelines in Western Kenya. Tropical Medicine and. International Health 8:37-47.

60. Tasawer Z, Mannan F, Bhutta A (2003) Prevalence of human malaria at Multan, Pakistan. Journal of Medical Science 3:123-126.

61. Dr. Vikas Sharma MD.

62. Boric Matera Madica. Vol. 03.

\section{Your next submission with Juniper Publishers} will reach you the below assets

- Quality Editorial service

- Swift Peer Review

- Reprints availability

- E-prints Service

- Manuscript Podcast for convenient understanding

- Global attainment for your research

- Manuscript accessibility in different formats

( Pdf, E-pub, Full Text, Audio)

- Unceasing customer service

Track the below URL for one-step submission https://juniperpublishers.com/online-submission.php 